\title{
Complications in paediatric regional anaesthesia: a narrative review
}

\author{
V Ponde, (iD) A Uemura, (iD) N Singh (iD) \\ Corresponding author, email: vrushaliponde@yahoo.co.in
}

\section{Summary}

Paediatric anaesthesia and paediatric regional anaesthesia are intertwined. Currently, almost all paediatric patients posted for surgery could and should be given a regional block unless and until contraindicated. This is because the scope, techniques, and their benefits have a wide range and complications are rare. The first report that used regional anaesthesia in children was in 1898, and over the last 120 years it has been developed with many scholars' wisdom, ideas and publications. Paediatric regional anaesthesia (PRA) has many advantages but requires experience and expertise. For a long-time, exclusively landmark-guided techniques were used and gradually the development of new techniques such as the use of neuro-stimulator and ultrasound-guided (USG) blocks developed into PRA. Especially, the application of ultrasonography (US) has revolutionised the practice of PRA. Few limitations of regional anaesthesia can be tackled by the use of US, leading to shorter time to perform the block, reduced time for block onset and use of a smaller volume of local anaesthetic. Life-threatening complications of regional anaesthesia are rare and the riskbenefit ratio is favourable. However, a thorough insight into RA complications, no matter how rare they are, is essential for safe practice. This is because they can be life-threatening, and no matter how small the percentage is, when complications occur, for that individual patient statistics is irrelevant.

Keywords: paediatric regional anaesthesia, complications, regional block

Although rare, complications can occur in paediatric regional anaesthesia (PRA). ${ }^{1}$ An awareness of the various steps where things could go wrong, and the measures taken to rectify them, can go a long way in preventing and treating PRA effectively.

\section{Complications due to needle and its trajectory}

\section{The needle puncture point}

Infections, swellings, tenderness, inflammation at the site of needle puncture has been reported. Although not too harmful in peripheral nerve blocks, this can be dangerous for central neuraxial procedures. Microorganisms can gain access to deeper layers along the needle insertion path. In central neuraxial blocks, this can present as meningitis, epidural abscess as the organism can migrate along the catheter track. The local anaesthetic (LA) injected from the multidose vials could be a source of infection too, even though they contain bacteriostatic agents. Adequate aseptic precautions go a long way to prevent infections.

\section{The needle trajectory}

Along the path of needle advancement till the target, depending on the anatomical layers along the trajectory, various structures can be inadvertently damaged. To quote a few examples, the vascular structures (causing haematoma, inadvertent intravascular injections) could be damaged, e.g. in brachial plexus blocks, the plural (causing pneumothorax) in infraclavicular, subclavian perivascular or paravertebral blocks, inadvertent damage to the bony structure such as the base of the sacrum in caudal epidural block, inadvertent puncture of the dural sac while performing caudal block, peritoneal puncture in cases of abdominal wall blocks, or kidney damage while performing lumbar plexus block. These are to list a few, however; it is possible to damage any structure along the path towards the nerve or target fascial plane and the nerve itself, during the needle advancement. This can be prevented to a large extent by real-time of US guidance and thorough knowledge of anatomy. It is better to be mindful of the varying anatomy in children as the range of weight and size is wider, and structures are more superficial. Moreover, congenital anomalies and their tell-tale signs should be checked out.

\section{Complication due to local anaesthetic drugs}

These include methemoglobinaemia, allergic reactions and local anaesthetic systemic toxicity (LAST). Methemoglobinaemia is rare, the LA (especially prilocaine) works as an exogenous factor to induce acquired methemoglobinaemia. ${ }^{2}$ Allergic reactions to $\mathrm{LA}$ are more due to the preservatives, however, allergic reaction to preservative-free mepivacaine has also been reported. ${ }^{3}$ Human errors in aspirating wrong drugs or expired drugs are always a possibility, and local protocols should be made to prevent them.

\section{Local anaesthetic systemic toxicity in children}

Although rare, LAST can be fatal, especially in infants, because they are more susceptible. Few case reports of LAST predominantly in newborns ${ }^{4}$ and infants ${ }^{5}$ have been reported. To prevent LAST, the maximal allowable LA dosing has to be followed. Test dosing and incremental injections in aliquots are recommended. ${ }^{6}$ The presentation of LAST can be masked with the concomitant sedation or general anaesthesia. The central nervous system and the cardiovascular systems are affected, 
presenting as seizures, tachyarrhythmias, and ultimately death from apnoea and cardiovascular collapse. The manifestation of seizures calls for airway control and oxygenation, control of seizures with midazolam and thiopentone, arterial blood gases and, if possible, drug level sampling is required.

The cardiovascular toxicity has to be treated by intralipids. The recommended dosage is $1.5 \mathrm{ml} / \mathrm{kg}$ to $2 \mathrm{ml} / \mathrm{kg}$ of $20 \%$ lipid emulsion bolus intravenously over one minute. The bolus can be repeated once or twice if required. The continuous infusion recommended dose is $0.25 \mathrm{ml} / \mathrm{kg} / \mathrm{min}$ (upper limit of $10 \mathrm{ml} / \mathrm{kg}$ lipid emulsion over the first 30 minutes). Propofol as an alternative to intralipid is unacceptable and harmful. Epinephrine has not been shown to be as effective as intralipid. The treatment algorithm for LAST should be laminated and kept ready for reference. If $20 \%$ intralipid is not available we should not perform regional anaesthesia.

Having enumerated most of the complications associated with PRA, it's worthwhile to take note that they are rare, surprisingly, in spite of the fact that most of the blocks are performed under general anaesthesia or sedation. Recently Paediatric Regional Anaesthesia Network (PRAN) did a multi-institutional study of PRA in 2010, 2012, 2015 and 2018.7, In this study they did not identify any permanent motor or neurologic deficits. The data from this study demonstrate a level of safety in PRA and confirms the safety of placing blocks under general anaesthesia in children. ${ }^{8}$

The major difference between the practices of regional anaesthesia in the last ten years (2000-2010) and these ten years (2010-2020) in PRA is application of US. ${ }^{9}$ Also, ultrasoundguided (USG) peripheral nerve blocks have increased in these ten years. Caudal epidural blocks have stood the test of time and have an approving safety record, ${ }^{10}$ however, application of USG blocks does add to the safety and accuracy. Furthermore, USG peripheral nerve blocks are observed to be superseding the central neuraxial blocks. ${ }^{11}$ Peripheral nerve blocks and perineural catheters are rendered safer with US guidance. ${ }^{12}$ There are also several advantages of USG caudal blocks. Anatomical variations in the lumbosacral region such as sacral meningocele, extradural cysts are usually asymptomatic in neonates and infants. They can be associated with skin discolouration of the sacral area, sacral dimple or hair tuft. US scanning in such cases helps us pick up the pathology and gives us a clear idea of what we are dealing with. ${ }^{13}$ Certain complications, such as rectal puncture, can be avoided..$^{14}$ However, real-time USG central neuraxial blocks require more skill than USG peripheral nerve blocks, pre-procedural scan can determine the depth of skin to the epidural space, thereby preventing dural punctures. Real-time visualisation of the epidural catheter and location of the catheter tip can be detected in newborns and infants..$^{15}$ Complications related to catheter placement in central neuroaxis, ${ }^{16-18}$ have also decreased, and accuracy has improved with US guidance. Increasing application of PRA does create unique issues, such as parental demand and teenager refusal of epidural anaesthesia. ${ }^{19}$ This calls for introspections and understanding of our attitude towards communication and legalities. Lastly, as many benefits that PRA has always offered, COVID-19 bring us to consider the importance of PRA again. ${ }^{20}$

In conclusion, complications in PRA are rare in spite of the fact that blocks in this age group are mostly performed under sedation or general anaesthesia. Systematic training, the right equipment, knowledge of anatomy, understanding of the local anaesthetic drugs, vigilant monitoring, training in USG regional anaesthesia and an attitude of keeping abreast with the latest information goes a long way in improving safety.

\section{ORCID}

V Ponde (iD https://orcid.org/0000-0001-6300-7240

A Uemura (iD https://orcid.org/0000-0003-3483-9210

N Singh (iD https://orcid.org/0000-0003-2013-4295

\section{References}

1. Walker BJ, Long JB, Sathyamoorthy $M$, et al. Complications in pediatric regional anesthesia: an analysis of more than 100,000 blocks from the Pediatric Regional Anesthesia Network. Anesthesiology. 2018;129(4):721-32. https://doi. org/10.1097/ALN.0000000000002372.

2. Soeding $P$, Deppe $M$, Gehring $H$. Pulse-oximetric measurement of priloca-induced methemoglobinia in regional anesthesia. Anesth Analg. 2010;111(4):1065-8. https://doi.org/10.1213/ane.0b013e3181eb6239.

3. Sharma V, Harper NJN, Garcez T, Arkwright PD. Allergic reaction to mepivacaine in a child. BJA. 2013;110(6):1059-60. https://doi.org/10.1093/bja/aet147.

4. Hübler M, Gäbler R, Ehm B, et al. Successful resuscitation following ropivacaineinduced systemic toxicity in a neonate. Anaesthesia. 2010;65(11):1137-40. https://doi.org/10.1111/j.1365-2044.2010.06449.x.

5. Shah S, Gopalakrishnan S, Apuya J, Shah S, Martin T. Use of intralipid in an infant with impending cardiovascular collapse due to local anesthetic toxicity. J Anesth. 2009;23:439-41. https://doi.org/10.1007/s00540-009-0754-3.

6. Barrington MJ, Kluger R. Ultrasound guidance reduces the risk of local anesthetic systemic toxicity following peripheral nerve blockade. Reg Anesth Pain Med. 2013;38:289-99. https://doi.org/10.1097/AAP.0b013e318292669b.

7. Polaner DM, Taenzer AH, Walker BJ, et al. Pediatric Regional Anesthesia Network (PRAN): A multi-institutional study of the use and incidence of complications of pediatric regional anesthesia. Anesth Analg. 2012;115(6):1353-64. https://doi. org/10.1213/ANE.0b013e31825d9f4b.

8. Ivani G, Suresh S, Ecoffey C, et al. The European Society of Regional Anaesthesia and Pain Therapy and the American Society of Regional Anesthesia and Pain Medicine Joint Committee Practice Advisory on controversial topics in pediatric regional anesthesia. Reg Anesth Pain Med. 2015;40:526-32. https://doi org/10.1097/AAP.0000000000000280.

9. Ponde V. Recent trends in paediatric regional anaesthesia. Indian J Anaesth 2019;63(9):746-53. https://doi.org/10.4103/ija.IJA_502_19.

10. Suresh S, Long J, Birmingham PK, De Oliveira GS. Are caudal blocks for pain control safe in children? An analysis of 18,650 caudal blocks from the Pediatric Regional Anesthesia Network (PRAN) database. Anesth Analg 2015;120(1):151-6. https://doi.org/10.1213/ANE.0000000000000446.

11. Greaney D, Everett T. Paediatric regional anaesthesia: updates in central neuraxial techniques and thoracic and abdominal blocks. BJA Education. 2019;19(4):126-34. https://doi.org/10.1016/j.bjae.2018.12.003.

12. Walker BJ, Long JB, De Oliveira GS, et al; PRAN Investigators. Peripheral nerve catheters in children: an analysis of safety and practice patterns from the Pediatric Regional Anesthesia Network (PRAN). Br J Anaesth. 2015;115(3):457-62. https://doi.org/10.1093/bja/aev220.

13. Ponde VC, Bedekar VV. Encountering caudal cyst on ultrasound: What do we do? Indian J Anaesth. 2017;61(8):685-7. https://doi.org/10.4103/ija.IJA_144_17.

14. Varghese N, Joseph N, Kandavar S. Rectal puncture during caudal anaesthesia. Indian J Anaesth. 2016;60(5):371-2. https://doi.org/10.4103/0019-5049.181618.

15. Kil HK. Caudal and epidural blocks in infants and small children: historical perspective and ultrasound-guided approaches. Korean J Anesthesiol. 2018;71(6):430-9. https://doi.org/10.4097/kja.d.18.00109.

16. Simpao AF, Gálvez JA, Wartmann $E$, et al. The migration of caudally threaded thoracic epidural catheters in neonates and infants. Anesth Analg. 2019;129(2):477-81. https://doi.org/10.1213/ANE.0000000000003311.

17. Ponde VC, Bedekar VV, Desai AP, Puranik KA. Does ultrasound guidance add accuracy to continuous caudal-epidural catheter placements in neonates and infants? Pediatr Anesth. 2017;27(10):1010-4. https://doi.org/10.1111/pan.13212.

18. Ravishankar CK. Knotted epidural catheter in an infant: a case report. Indian J Anaesth. 2017;61(5):444-6. https://doi.org/10.4103/ija.IJA_458_16.

19. Berkowitz I, Burgart A, Truog TJ, et al. Parents demand and teenager refuses epidural anesthesia. Pediatrics. 2020;145(6):e20193295. https://doi.org/10.1542/ peds.2019-3295.

20. Ponde VC, Diwan S, Gopal TV, Subramanian JB, Danish MA. Regional anaesthesia in the coronavirus disease (COVID-19) pandemic: clinical guidelines by AORA India. J Anaesthesiol Clin Pharmacol. 2020;36(5):109-15. https://doi.org/10.4103/ joacp.JOACP_277_20. 